\title{
PENELITIAN JEJAK MANUSIA DAN BUDAYA AUSTRONESIA DI SITUS SUBANGLARANG, KABUPATEN SUBANG \\ PANTAI UTARA JAWA BARAT
}

\author{
Research on Human and Austronesian Culture in Subangalarang Sites, \\ Subang, North Coast of West Java
}

\author{
Lutfi Yondri \\ Balai Arkeologi Jawa Barat \\ Jalan Raya Cinunuk KM.17 Cileunyi, Kabupaten Bandung 40623 \\ E-mail: yondrilutfi@gmail.com
}

\begin{abstract}
s
The initial process of occupying the Austronesian culture in the western part of Java or especially West Java is still a mystery. Some experts believe this is difficult to find because the early Neolithic sites on the north coast of West Java have been buried under alluvial deposits. The idea of locating the initial landing site of the Austronesian landing on the North coast of Java has been developed in recent years, including that carried out by the National Archaeological Research Centre in November 2015 in the Cilamaya area (Karawang). Another location that is supposed to be part of the initial residential area of the Austronesian landings in the past is the Subanglarang site, Binong District, Subang Regency, West Java. The location is in a watershed area which is quite ideal as a location in the past and is located at the height of the coastline which is included in the interpretations of experts as the location of Austronesian culture in the past. Trenching of archaeological remain was done by survey and excavation and was show some evidence such as human skeletal remains with the findings as well as pig teeth, red slip pottery, hand axes, and beads from various materials, shapes, sizes and materials.
\end{abstract}

Keywords: Human, Culture, Austronesian, North Coast, West Java.

\section{Abstrak}

Proses awal penghunian rumpun Austronesia di wilayah Jawa bagian barat atau khususnya Jawa Barat sampai sekarang masih menjadi misteri. Sebagian ahli berpendapat hal itu sulit ditemukan disebabkan karena situs-situs neolitik awal di pantai utara Jawa Barat telah terkubur oleh di bawah endapan aluvial. Gagasan untuk pencarian lokasi awal pendaratan Masyarakat Austronesia di pantai Utara Jawa sudah dikembangkan sejak beberapa tahun belakangan, termasuk yang dilakukan oleh Pusat Penelitian Arkeologi Nasional pada November 2015 di daerah Cilamaya (Karawang). Lokasi lain yang patut diduga sebagai bagian dari kawasan hunian awal dari pendaratan Austronesia di masa lalu adalah situs Subanglarang, Kecamatan Binong, Kabupaten Subang, Jawa Barat. Lokasi tersebut berada di kawasan aliran sungai yang cukup ideal sebagai lokasi hunian pada masa lalu dan berada di ketinggian garis pantai yang termasuk dalam penafsiran para ahli sebagai lokasi hunian masyarakat berbudaya Austronesia pada masa lalu. Untuk menjajaki tinggalan tersebut dilakukan survey dan ekskavasi. Dari hasil dua kegiatan tersebut memberikan beberapa bukti arkeologi berupa sisa rangka manusia dengan temuan serta berupa gigi babi, tembikar selip merah, beliung persegi, dan manikmanik dari berbagai bahan, bentuk, ukuran dan bahan yng terkait erat dengan keberadaan budaya Austronesia pada masa lalu di lokasi tersebut.

Kata kunci: Manusia, Budaya, Austronesia, Pantai Utara, Jawa Barat 


\section{PENDAHULUAN}

Citus Subanglarang secara administratif merupakan bagian dari wilayah Kecamatan Binong, terletak lebih kurang 20 $\mathrm{km}$ disebelah utara Kota Subang Sekarang. Kawasan situs Subang larang dari sisi geografis berada di tepi aliran Ci Jati. Secara garisbesarkawasaninijugamerupakanbagian dari morfologi pendataran bergelombang rendahnya Kawasan Kabupaten Subang. Kawasan Kabupaten Subang secara umum diselingi oleh tiga aliran sungai besar yang semuanya mengalir ke pantai utara Jawa, yaitu Ci Lamaya, Ci Asem, dan Ci Punagara. Ci Jati sendiri merupakan salah satu anak sungai dari Ci Asem (Silitonga, 1973).
Dari hasil penelitian yang telah dilakukan selama ini di kawasan Kabupaten Subang, baik baik oleh paleontolog maupun arkeolog, temuan-temuan yang telah mereka hasilkan bila ditempatkan secara geomorfologis, umumnya temuan tersebut ditemukan di sepanjang aliran $\mathrm{Ci}$ Asem, di antaranya, di bagian hulu ditemukan fosil vertebrata (Mulyana, 2003), kemudian ke arah hilir tercatat temuan artefak yang berciri paleolitik, kapak corong, nekara (Asdi, Armin., dkk: 1980), serta sebaran lokasi dengan temuan berupa fragmen tembikar dan manik-manik yang terbuka ke permukaan karena aktivitas pertanian (Yondri, 2016).

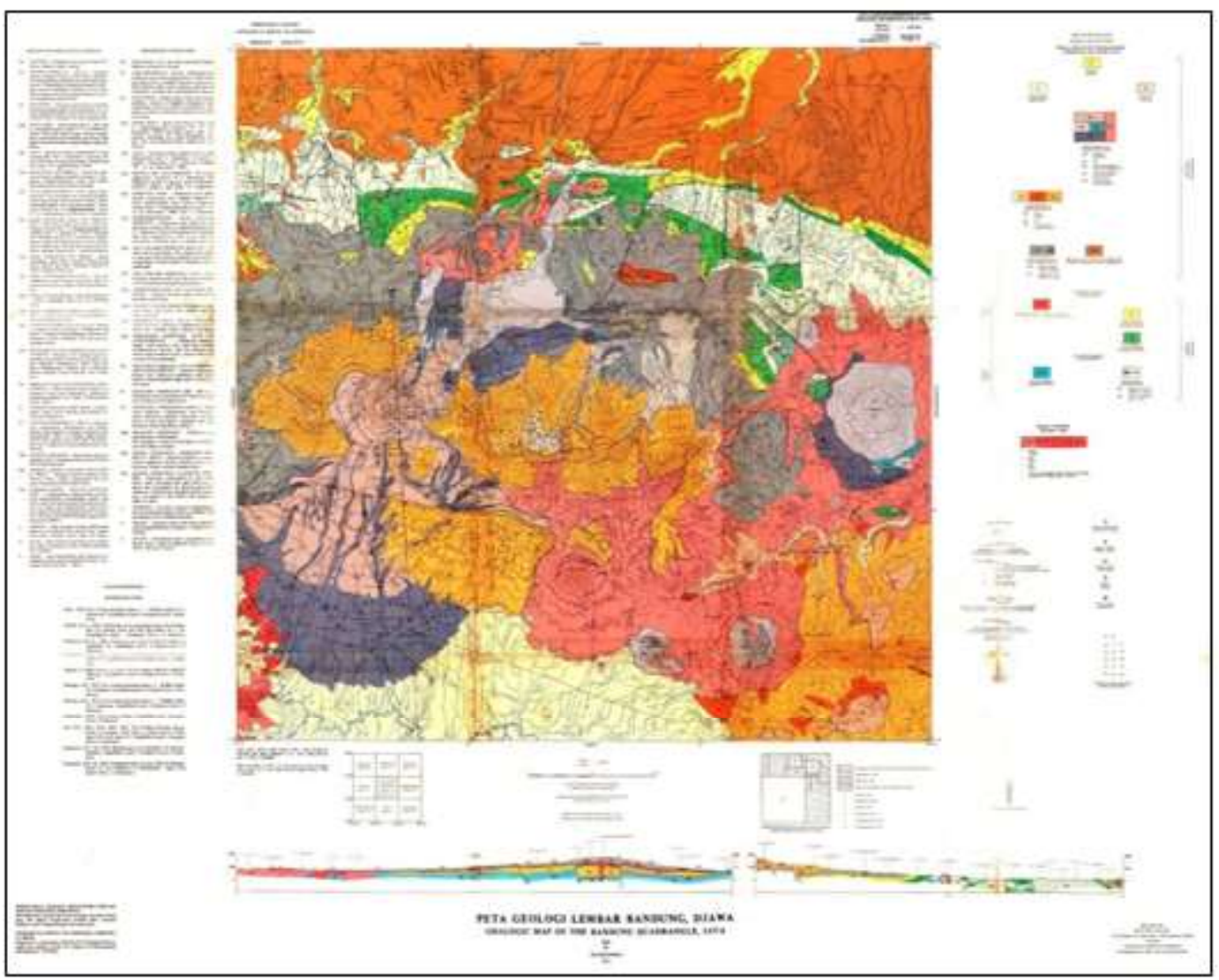

Gambar 1. Peta Geologi Lembar Bandung, Jawa Barat. Bandung: Pusat Penelitian dan Pengembangan Geologi (Sumber: P.H. Silitonga. 1973). 
Komposisi masayarakat Jawa Barat sekarang saat sekarang mayoritas penduduknya berciri Mongoloid serta menuturkan bahasa yang termasuk dalam rumpun Melayu (Austronesia). Sampai sekarang kapan dan dimana pertama kalinya rumpun Austronesia di Indonesia, khususnya di kawasan Jawa Barat melakukan penghunian masih mengandung misteri, dan membutuhkan penelitian untuk mengungkapkannya.

Banyak ahli yang berpendapat bahwa keberadaan masyarakat Austronesia pada masa lalu di Indonesia, persebarannya sampai di Indonesia disebabkan oleh proses ekspansi komunitas penutur rumpun bahasa tersebut ke luar dari daerah asalnya. Sementara itu berkaitan dengan dari mana daerah asal masyarakat Austronesia yang datang ke wilayah Indonesia di masa lalu terdapat tiga simpulan yang berbeda, pertama ada yang berpendapat bahwa Austronesia berasal dari Pulau Taiwan, kedua, Austronesia berasal dari dari kawasan Asia Tenggara Kepulauan, dan ketiga, Austronesia berasal dari dari kawasan Melanesia.

Di antara tiga simpulan tersebut banyak peneliti yang lebih cenderung pada pandangan yang pertama yaitu pandangan yang dikemukakan oleh Bellwood (1995) dengan teori Out of Taiwan atau juga dikenal dengan pandangan The Express Train from Taiwan to Polynesia, yang intinya bahwa masyarakat penutur bahasa Austronesia berekspansi dari Taiwan sejak 5.000 BP menuju Asia Tenggara Kepulauan, Melanesia Kepulauan, Micronesia hingga Polynesia, dengan cepat selama satu millennium berikutnya sampai ke Indonesia melalui jalur Filipina.

Satu catatan yang menarik dari hasil penelitian selama ini di kawasan Jawa Barat adalah telah banyak ditemukan berbagai temuan artefaktual yang terkait dengan kebudayaan rumpun Austronesia. Beberapa di antaranya ditemukan beberapa tipologi beliung persegi yang dicatat oleh H.R van Heekeren (1974) yang berasal dari beberapa lokasi seperti; Banten, Kelapa Dua, Pejaten, Kampung Keramat, dan Buni (Jakarta dan Tangerang), Pasir Kuda (Bogor), Cibadak, Cirebon, Tasikmalaya. Sementara itu di beberapa situs yang lain juga telah ditemukan gerabah dengan dasar membulat berhias slip merah, cap, gores dan tera tali dengan bibir melipat ke luar, beliung dengan potongan lintang persegi empat yang diasah, lancipan batu, dan lain sebagainya yang mencirikan tentang hadirnya rumpun Austronesia di wilayah ini.

Sampai sekarang belum banyak penelitian dilakukan yang berkaitan dengan bagaimana dan dimana proses awal penghunian rumpun Austronesia di wilayah Jawa bagian barat atau khususnya Jawa Barat. Hal ini sampai sekarang masih menjadi permasalahan yang sangat menarik untuk diteliti. Walaupun Bellwood (2000: 337) menduga bahwa hal itu sulit diteliti karena mungkin hal itu terjadi karena situs-situs neolitik awal di pantai utara Jawa Barat telah terkubur oleh di bawah endapan aluvial, sehingga sukar untuk ditemukan dan diteliti (Bellwood, 2000: 337). Tentunya dugaan Bellwood perlu diuji dengan memunculkan apakah permukiman awal itu berada di kawasan pantai dan kemudian terkubur oleh endapan aluvium, apakah tidak memungkinkan pemukiman awal tersebut agak bergeser ke daerah daratan dengan dasar pemikiran bahwa pemukiman itu lebih cnederung mencari daerah-daerah yang cukup aman, memadai untuk mengembangkan kegiatan bercocok tanam, serta memiliki sumber air tawar 
untuk mendukung kehidupan sehari-hari saat itu. Dalam hal ini, kuat dugaan bahwa kehidupan neolitik awal itu bukan berada di kawasan pantai, akan tetapi agak bergeser ke kasan dataran yang berada di aliran sungai.

Gagasan untuk pencarian lokasi awal pendaratan Masyarakat Austronesia di pantai Utara Jawa sudah dikembangkan oleh Sofwan Nurwidi sejak beberapa tahun belakangan, dan juga sudah mulai dikembangkan oleh Pusat Penelitian Arkeologi Nasional melalui penelitian gabungan yang dilakukan pada November 2015 yang lalu (Simanjuntak, dkk, 2015). Dari hasil ekskavasi yang dilakukan di Kawasan Cilamaya, Karawang pada 2015 tersebut belum diperoleh temuan arkeologis yang terkait dengan hal tersebut. Mungkin hal ini terjadi karena lokasi penggalian bukan merupakan bagian dari kawasan yang patut dicurigai sebagai bagian dari kawasan hunian pertama atau kawasan awal dari pendaratan Austronesia di masa lalu. Nurwidi berpandangan, lokasilokasi yang patut dijadikan sebagai lokasi penelitian untuk mencari jawaban tentang lokasi awal pendaratan atau awal penghunian rumpun Austronesia di pantai utara Jawa adalah lokasi-lokasi di kawasan dengan kisaran ketinggian di atas 3-4 m dari muka laut sekarang. Hal ini dia kaitkan dengan penelitian Tjia (2006) tentang kondisi 5000 BP Semenanjung Malaysia dan Thailand yang gerak tektoniknya stabil, muka air laut lebih tinggi $5 \mathrm{~m}$ dari muka air laut sekarang. Jika hal ini juga terjadi di pantai utara Jawa, maka situs-situs pendaratan Austronesia antara 3.000-2.500 BP harus dicari pada kawasan pantai yang konturnya lebih tinggi dari 3-4 meter di atas permukaan laut saat ini.

Terkait dengan hal tersebut, penelitian prasejarah yang ditujukan untuk mengungkapkan keberadaan rumpun
Austronesia di kawasan pantai utara Jawa Barat barat harus ditarik ke belakang dari garis pantai utara sekarang. Salah satu daerah yang dipandang memiliki potensi untuk penelitian tersebut adalah kawasan Kabupaten Subang.

Mengingat sebagian besar tinggalan yang terkait dengan keberadaan manusia dan budaya Austronesia di kawasan tersebut tidak berada di permukaan tanah yang dengan mudah untuk diamati, akan tetapi seluruhnya terpendam di bawah permukaan tanah, maka untuk mengamatinya harus melalui serangkaian kegiatan ekskavasi. Oleh karena luasnya lokasi penelitian, maka kegiatan ekskavasi tersebut harus dilakukan secara bertahap, dan dilakukan dengan hatihati sehingga berbagai temuan yang terkait dengan hal itu dapat ditemukan untuk dianalisis.

\section{PEMBAHASAN}

Austronesia adalah istilah linguistik yang merujuk pada satu rumpun bahasa yang dituturkan oleh komunitas di wilayah IndoMalaya dan Pasifik. Pada perkembangan kemudian, istilah Austronesia meluas dan merujuk pada semua komunitas yang berbudaya dan menuturkan bahasa Austronesia (Bellwood; James J. Fox; Darrel Tryon (Eds); 1995:17). Tema mengenai asal usul kebudayaan yang disebarkan oleh kelompok penutur Austronesia merupakan isu penelitian yang mengemuka pada dua dekade terakhir ini. Tema ini menjadi fenomena menarik karena luasnya wilayah persebaran dan jumlah penutur rumpun bahasa Austronesia yang membentang dari Madagaskar di barat sampai pulau Easter di timur, dan dari Taiwan dan Mikronesia di utara sampai New Zaeland di selatan. Persebaran rumpun bahasa ini mencapai 
lebih dari separuh belahan dunia sebelum kolonialisasi Eropa pada abad ke-16 (Tanudirjo, 2008:33).

Ada beberapa ahli yang menguraikan teori tentang persebaran dan tanah asal budaya Austronesia. Von Heine Geldern adalah ahli pertama yang menguraikan teori tersebut pada tahun 1932 yang mendasarkan pandangan pada kajian tipologi beliung. Kemudian Thor Heyerdahl (1947) yang menyatakan teori bahwa bangsa Polinesia datang melalui pantai barat Amerika Selatan. Dia berusaha membuktikan pernyataan tersebut dan melakukan ekspedisi naik rakit dari Peru ke Polinesia (Mulia,1980:599-646). Heyerdahl pada tahun 1947 mengemukakan teori bahwa orang Austronesia bermigrasi dari Indonesia melewati great circle route menuju Jepang, Alaska, pesisir Pasifik Utara lalu ke Polinesia. Ada dua jalur dari pola migrasi tersebut, yaitu jalur utara dari pesisir Pasifik Utara menuju Hawaii, dan jalur selatan dari Bolivia dan Peru menuju Easter Island. Teori ini didukung oleh analisis navigasi, perbandingan ras, dan budaya material (Rouse, 1986: 23-24). Disertasi Dr. C.H.C. Heeren Palm (1955) berjudul Polynesische Migratie, membantah keras teori Heyerdahl tersebut (Mulia, 1980: 599646).

Selanjutnya, Roger Duff (1970) melakukan kajian tipologi beliung persegi, baik di Asia Tenggara daratan maupun kepulauan. Berdasarkan klasifikasi tipologi beliung persegi terutama pada bentuk tajaman (cutting edge), irisan (cross section) dan pangkal (poll), dia menyatakan bahwa budaya Austronesiaberasal dari semenanjung Malaysia bahagian selatan. Ciri budaya ini adalah beliung paruh (Malayan beacked adze) dan belincung (Indonesia pick adze) (Duff, 1970: 15). Walaupun teori ini tidak dapat bertahan karena banyaknya penemuan baru yang bertentangan, analisis tipologi Duff telah memberi sumbangan besar pada kajian tipologi beliung di Asia Tenggara. Ahli lain yang mengajukan teori persebaran budaya Austronesia berdasarkan temuan tembikar adalah Wilhelm G. Solheim II tahun 1984. Teorinya menyatakan bahwa tanah asal budaya Austronesia adalah kawasan sekitar Palawan, Western Borneo, dan kepulauan Sulu, ditandai oleh temuan tembikar pre-Sahuynh-Kalanay. Kawasan ini mulai dihuni pada awal abad kedua sebelum Masehi. Walaupun demikian, kawasan ini hanyalah tahap perkembangan kedua dari budaya Austronesia, dan belum cukup data untuk menentukan wilayah asalnya (Solheim II, 1984: 43).

Teori yang dilandasi kajian linguistik dilontarkan oleh Robert Blust (19841985) yang menyatakan bahwa tanah asal komunitas Austronesia adalah Taiwan. Teori ini dikembangkan lebih lanjut oleh Peter Bellwood dengan dengan pandangan bahwa budaya Austronesia mengalami proses pembentukan di Taiwan dan pantai selatan China merupakan tempat asal bahasa proto-Austronesia. Secara arkeologi, kawasan tersebut memiliki bukti-bukti pertanian, beliung dan tembikar berumur 7000 tahun lalu (Bellwood, 2000: 9798). Sampai sekarang, teori Out of Taiwan banyak dirujuk oleh sarjana,dan akhirnya mencoba mengelompokkan beberapa gelombang migrasi Austronesia yang sampai ke Indonesia, Berdasarkan pandangan yang dikemukakan Blust (1976), Belwood (2000), Tanudirjo (2012) menyimpulkan bahwa Austronesia sampai dan berkembang di Indonesia disimpulkan melalui lima tahapan.

* Tahap I merupakan tahap migrasi para petani dari Cina selatan mencapai Taiwan (5000 tahun SM), 
* Tahap II, migrasi dari Taiwan ke Filipina $(2.500 \mathrm{SM})$,

* Tahap III, migrasi dari Filipina ke arah selatan dan tenggara (menjelang 2000 SM),

* Tahap IV, migrasi dari Maluku Utara ke selatan dan timur (2000 SM), dan,

* Tahap V migrasi dari Papua Utara ke barat dan ke timur.

Dari lima tahapan tersebut, menarik untuk ditelusuri lebih lanjut untuk wilayah Indonesia bagian barat adalah tahap IV (2000 SM). Pergerakan migrasi (proto) Melayo-Polynesia-Barat bergerak ke selatan atau barat bermigrasi ke Jawa dan Sumatera. Berdasarkan hal tersebut menjadi penting untuk menelusuri keberadaan jejak Austronesia di di bagian barat pulau Jawa atau khusunya di bagian pantai urata Jawa Barat (Herlina ddk, 2018, inpress).

Berdasarkan hasil penelitian prasejarah yang mulai dilakukan pada 2013 yang lalu di situs subanglarang (Subang) baik yang dilakukan melalui kajian singkat bersama Pemerintah Propinsi Jawa Barat, dan kemudian penelitian menggunakan dana Balai Arkeologi Bandung (2016) dan terakhir penelitian yang diinisisai oleh Dinas Pendidikan dan Kebudayaan Kabupaten Subang (2018), berhasil menemukan beberapa indikasi kuat yang terkait dengan keberadaan budaya Austronesia di situs tersebut. Temuan yang berhasil diungkap dari kegiatan tersebut antara lain tinggalan artefaktual berupa fragmen tembikal berhias, dan berslip merah, beliung persegi, kapak perunggu, manik-manik dari bahan batuan, terakota, kaca, dan logam mulia; temuan non artefaktual berupa gigi babi, moluska, serta lima rangka manusia yang terkubur dengan orientasi barat laut-tenggara dengan posisi kepala berda di sisi barat laut. Satu diantara rangka tersebut ditemukan utuh (rangkaian tulang rangka masih dalam susunan anatomisnya, berurut dari bagian kepala hingga tulang kaki). Rangka tersebut terkubur dengan posisi teletang, kepala agak ditekuk ke arah utara dengan arah muka menghadap ke arah bujur badan. Di sekitar kepala terdapat sebaran manik-manik, di sisi atas kepala terdapat bekal kubur berupa senjata yang terbuat dari logam. Sementara di bagian kaki terdapat dua jenis bekal kubur yaitu senjata yang terbuat dari bahan logam yang ditempatkan di sisi kaki kiri, dan wadah tembikar di atas kaki (saat ditemukan sudah dalam keadaan pecah) (Yondri, 2016, 2018).

Merujuk data yang telah ditemukan dari tiga kali kegiatan penelitian di situs Subanglarang tersebut, dapat disimpulkan bahwa temuan yang telah diperoleh dapat diduga merupakan temuan-temuan budaya yang merupakan bagian dari satu sistem permukiman pada masa lalu. Ekskavasi yang dilakukan baru mengungkap sebagian dari sistem permukiman yaitu yang terkait dengan bagian dari aktivitas penguburan serta ragam artefaktual dan non artefaktual yang terkait dengan keberadaan manusia dan budaya Austronesia pada masa lalu di lokasi tersebut.

\section{SIMPULAN}

Berdasarkan hasil penelitian yang dilakukan dengan melakukan survey dan ekskavasi dapat diambil simpulan sementara bahwa situs Subanglarang yang terletak ditepi aliran $\mathrm{Ci}$ Jati, anak sungai dari $\mathrm{Ci}$ Asem yang berada di kawasan alluvium pantai utara Jawa Barat memiliki potensi untuk dikembangkan dalam mencari jejak awal pendaratan Austroneia di Pantai Utara Jawa Barat karena di Kawasan tersebut terdapat sebaran artefaktual berupa sebaran 
beliung persegi, tembikar berselip merah, dan manik-manik. Hal ini lebih diperkuat lagi dengan temuan rangka manusia dari pembukaan kotak-kotak ekskavasi.yang disertai dengan beragam temuan artefaktual berupa wadah tembikan dan senjata yang terbuat dari logam yang disungsikan sebagai bekal kubur, serta beragam bentuk dan bahan manik-manik yang diperkirakan berkaitan dengan bentuk perhiasan yang digunakan pada saat itu. Bila diacu kronologi budaya dari hasil pertanggalan secara absolut dari kedua rangka yang ditemukan pada tahun 2016 karena berada pada lapisan tanah yang hampir setara secara stratigrafis, maka pertanggalan kabon ${ }^{14} \mathrm{C}$ dengan pertanggalan sementara sekitar 45 SM dapat digunakan sebagai acuan.

\section{DAFTAR PUSTAKA}

Asdi, Armin., dkk: 1980. Sejarah Kabupaten Subang. Dinas Kebudayaan dan Pariwisata Kabupaten Subang.

Bellwood, Peter, James J. Fox, Darrel Tryon (Eds), 1995, The Austronesians: Historical and Comparative Perspectives, Camberra, ANU.

Bellwood, Peter, 2000. Prasejarah Kepualauan Indo-Malaysia (Edisi Revisi). Jakarta, Gramedia Pustaka Utama.

Bemmelen, R.W. van. 1949 Geology of Indonesia; vol. I A. General GeologyThe Bandung Zone, p. 637-645

Blust, Robert A. 1984-1985, The Austronesian Homeland: A Linguistic Perspective, Asian Perspective 26, p: 45-68.

Clark, Grahame.1969 A r c h a e o lo g y and Society: Reconstructing the Prehistoric Past. New York: Barners \& Noble Books. Division of Harper and Row Publishers Duff, Roger.
1970. Stone Age of Southeast Asia, Cantebury Museum Bulletin no. 3 Christchurch.

Heekeren, HR. Van. 1972The Stone Age of Indonesia. Rev. 2nd. The HagueMartinus Nijhoff

Herlina, Nina., dkk, 2018. Kabupaten Subang dari Masa ke Masa (in press)

Mulia, Rumbi, 1980, Beberapa catatan tentang arca-arca yang disebut arca tipe Polinesia, dalam PIA I, Jakarta, Pusat Penelitian Purbakala dan Peninggalan Nasional, hal: 599646.

Mulyana, Dadan. 2003. Laporan Penelitian Vertebrata di Pasir Cabe, Kabupaten Subang. Bandung: Balai Arkeologi Bandung (tidak diterbitkan)

Rouse, Irvin. 1986, Migrations in Prehistory, Inferring Population Movement from Cultural Remains, New Haven, Yale University Press.

Simanjuntak, Truman., dkk. 2015, Penelitian Bersama di Kabupaten Karang. Jakarta: Pusat Penelitian Arkeologi Nasional.

Solheim II, Wilhelm G., 1984 Reflections on the New Data of Southeast Asian Prehistory, Austronesian origin and consequence. Dalam Peter Van de Velve, (Eds.) Prehistoric Indonesia, Foris Publications, USA, p: 43.

Soejono, R.P. 1984 "Jaman Prasejarah di Indonesia". Sejarah Nasional Indonesia I. J akarta : PN. Balai Pustaka

Tanudirjo, Daud Aris, 2008, Austronesian Diaspora and its impact in island Southeast Asia and Oceania, dalam Truman Simanjuntak (edt.) Austronesian in Sulawesi, Depok, CPAS., hal:33-5

Tryon, Darrell, 2009. Austronesia kuno dan sub kelompok utama Austronesia. ANU 
Yondri, Lutfi, 2016. Laporan Hasil Penelitian Prasejarah di Kecamatan Binong, Kabupaten Subang, Jawa Barat. Bandung: Balai Arkeologi Bandung (tidak diterbitkan)

Yondri, Lutfi, 2018. Laporan Hasil Ekskavasi Cagar Budaya Di Situs Subanglarang, Kecamatan Binong. Kabupaten Subang - Propinsi Jawa Barat. Subang: Dinas Pendidikan dan Kebudayaan Kabupaten Subang (tidak diterbitkan).

\section{HASIL DISKUSI}

\section{Pertanyaan}

1. Budianto Hakim (Balai Arkeologi Sulawesi Selatan)

a. Penelitian di Bone banyak menemukan manik-manik yang terbuat dari tanah liat bukan untuk kalung tapi alat pemintal, karena itu perlu penelitian lebih lanjut. Manik-manik kaca yang ditemukan di Subang sama dengan manik-manik yang ditemukan dalam penelitian di Bonehau. Tidak menemukan indikasi pembuatan manik-manik di wilayah tersebut oleh karena itu disimpulkan sebagai produk perdagangan, apakah manikmanik yang ditemukan di Subang juga seperti itu?

b. Kerusakan gigi terjadi karena faktor makanan dan jenis makanan. Terdapat pula kerusakan gigi yang disebabkan karena kebiasaan manusia prasejarah menggunakan gigi untuk mengasah seperti menghaluskan benang. Apakah bisa dibedakan kerusakan yang satu dengan lainnya?

\section{Lucas Wattimena (Balai Arkeologi Maluku)}

Alat-alat pendukung rangka manusia Subang yang menjustifikasi Austronesia di wilayah Jawa Barat? Berikan satu pernyataan yang kuat dan pas untuk memberikan gambaran Austronesia di Pulau Jawa berdasarkan penelitian tersebut? Manusia Subang mati dalam masa produktif yaitu sekitar umur 44 tahun, apakah ada salah satu faktor yang mengindikasikan kenapa manusia tersebut mati?

3. Dra. Dwi Yani Yuniawati Umar, M.Hum. (Balai Arkeologi D.I. Yogyakarta)

Ada seorang mahasiswa arkeologi yang melakukan penelitian mengenai rekonstruksi pola makanan yang mendukung budaya megalitik, hasilnya dapat diketahui beberapa penyakit gigi, karies gigi, atrisi, pola makan, jenis kelamin, dan umur. Apakah penelitian gigi manusia Subang bisa dikembangkan lebih lanjut untuk mencari tahu lebih banyak selain mengetahui umur dan penyakit akibat atrisi?

\section{Jawaban}

1. Tidakditemukanindikasiprosesproduksi pada manik-manik Subanglarang untuk sementara. Disebabkan penelitian yang telah berjalan masih merupakan penelitian kecil dan diharapkan ke depannya dapat dilangsungkan ekskavasi yang lebih besar lagi. Kuat dugaan manik-manik tersebut juga hasil proses perdagangan, mungkin melalui sungai (Sungai Ciasem), dan di masa selanjutnya di ujung sungai muncul pelabuhan-pelabuhan seperti Cirebon, 
Cimanuk, dan Sunda Kelapa, kebetulan muara Sungai Ciasem berada di antara pelabuhan-pelabuhan tersebut.

2. Perlu adanya penentu tegas bendabenda yang mencirikan Austroasiatik. Sementara ini masih menggunakan patokan Austronesia. Seperti belincung yang dianggap sebagai ciri Austronesia dan kapak persegi ciri Austroasiatik. Tidak menutup kemungkinan bahwa belincung dapat saja ditemukan di wilayah barat, seperti belincung yang ditemukan di Gunung Halu, Kabupaten Bandung Barat. Hal tersebut menunjukkan bahwa Austronesia dan Austroasiatik ada bersama-sama di wilayah barat. Harus perlu mencari mana yang pasti menjadi ciri dari keduanya. Namun dilihat dari proses migrasi, yang pertama berkembang out of Africa dan out of Asia adalah Austronesia, begitu sampai ke wilayah lain muncul modifikasi. Di situ kemudian dapat berbicara dalam suatu pendekatan yang baru bahwa culture is man adaptive system, bagaimana budaya itu muncul terjadi penyesuaian antara ide dan gagasan dengan sumber daya yang ada. Bagian-bagian tersebut harus dicari dan dipertegas hingga klasifikasi, konteks, dan rekonstruksi bisa dilakukan secara ajek.

Menerapkan usia produktif harus sesuai dengan masanya. Contoh pithecanthropus mati dalam usia 1819 tahun yang merupakan usia dewasa pada masanya. Terdapat jarak usia kedewasaan manusia dalam setiap masa. Di mesolitik, manusia dewasa rata-rata berada di usia 32 tahun. Semakin stres perut mengolah makanan akan memperpendek usia, mungkin sebanding lurus dengan perbandingan usianya, namun perlu penelitian lebih lanjut. Dengan CBCT juga dapat berbicara lebih banyak mengenai gigi, struktur gigi, dan dentin. Apakah dentin sudah sekunder untuk usia dewasa. Setelah dewasa gigi yang sudah atrisi digunakan kembali terbentuk dentin sekunder. Hal tersebut juga berpengaruh dalam kehati-hatian menghitung perkiraan umur. Kedewasaan individu pada masa lalu juga harus dilihat pada masanya. Tidak bisa langsung mengatakan usia tersebut merupakan usia produktif jika dibandingkan dengan masa sekarang. Mungkin usia produktif pada masa manusia Subang itu antara 20 - 30 tahun, sementara usia 40 atau 45 ke atas sudah tidak termasuk usia produktif.

3. Deskripsi lain (sex estimation, karies) sudah dilakukan sebelumnya pada manusia Pawon, sehingga tidak dilakukan pada gigi manusia Subang. Karies tidak diperiksa dalam penelitian manusia Subang karena tidak ditemukan karies pada giginya. Munculnya atrisi dan karies dapat dilihat dari pola higienisnya, pada manusia Subang tidak ditemukan karies, tapi suatu saat dari karang gigi dapat terlihat bakteri-bakteri yang terendapkan. Dari bakteri tersebut dapat dicari keterkaitannya dengan penyakit gigi atau penyakit lain yang ada di tubuhnya. 